\title{
TODO LO QUE SIEMPRE DESEÓ SABER SOBRE LA "Cultura de Prevención" Y NO SE ATREVIÓ A PREGUNTAR
}

\author{
Jaime Llacuna Morera \\ Instituto Nacional de Seguridad e \\ Higiene en el Trabajo -Centro Nacional de Condiciones de Trabajo \\ -CNCT- Barcelona
}

La Ley de Prevención de Riesgos Laborales plantea el fomento de una auténtica cultura preventiva. Pero esa "cultura de prevención" debería quedar inmersa en la Cultura, pues no existe una cultura específica, en este caso, que condicione la protección de la vida, la necesidad de evitar accidentes y enfermedades. Ahora bien, al transmitir la cultura, los mensajes emitidos deben estar en armonia con la interpretación que el colectivo haga de ellos, cosa que no siempre ocurre. Por tanto, no es que carezcamos de una cultura de prevención, lo que ocurre es que nuestra cultura de prevención no concuerda con la protección de la vida, con el valor "protección de la vida", y lo verdaderamente malo del tema es que la cultura maleducada de prevención está siendo reproducida en niños y niñas, por lo que es necesario no perder la confianza en que un valor puede ser adquirido y puede pasar, con el tiempo, a proporcionar las actitudes que deseamos.

The Law on Risk Prevention in the Workplace seeks to promote an authentic prevention culture. However, this "prevention culture" has to remain a part of the Culture, as there is no specific culture, in this case, that conditions human life protection and the necessity to avoid accidents and diseases. On transmitting this culture, the emitted messages must be in harmony with their interpretation. This does not always occur. Therefore, we do not lack a prevention culture. Our prevention culture is just not in accordance with the value "human life protection". This becomes really repercussive when the badly educated prevention culture is passed on to the children. Consequently, it is important not to lose faith in the possibility of acquiring this value and perhaps in the future we will see the attitudes we desire.

Palabras calve: cultura de prevención, educación, comunicación, realidad

Key words: prevention culture, education, communication, reality 
1. LAS "CULTURAS" DE LA CULTURA. La UNIÓN HACE LA REALIDAD O EL TODO ES SIEMPRE LA SUMA DE LAS PARTtes (AUNQUE ES DIFERENTE DE CADA UNA DE Ell.AS). El SULFaTO DE HIERRO ES LA METÁFORA DE LA CULTURA

Cuando, en 1995, aparecía la Ley de Prevención de Riesgos Laborales surgía, para elogio de legisladores y esperanza de profesionales, una expresión que (por lo menos a quienes llevábamos más de veinticinco años en la labor y, específicamente, en el ámbito de la formación), cubría las expectativas "socio-filosóficas" acumuladas desde hacia mucho tiempo. Decía el apartado 4 de la "Exposición de motivos": Pero tratándose de una Ley que persigue ante todo la prevención, su articulación no puede descansar exclusivamente en la ordenación de las obligaciones y responsabilidades de los actores directamente relacionados con el becho laboral El proposito de fomentar una auténtica cultura preventiva, mediante la promoción de la mejora de la educación en dicba materia en todos los niveles educativos, involucra a la sociedad en su conjunto $y$ constituye uno de los objetivos básicos y de efectos quizás más trascendentes para el futuro de los perseguidos por la presente ley ${ }^{1}$.

Cultura preventiva. Parece evidente que la respuesta que una colectividad da a un hecho concreto tiene el matiz o dirección que la cultura "determina". Determinismo que no debe implicar actuación mimética de los componentes, por supuesto. Determinismo, entre muchas comillas, que, a pesar de todo, desearíamos para determinadas conductas. Me explicaré: en El valor de educar Fernando Savater utiliza una metáfora que puede sernos útil, dice: Apuremos la metáfora basta el final, antes de darla de lado como antes o después bay que bacer con todas las imágenes literarias para que no se conviertan en estorbos del pensamiento. Sin raices las plantas mueren irremediablemente; sin follaje, flores y frutas el paisaje sería de una monotonía estéril e inaguantable. La diversidad cultural es el modo de expresarse la comün raiz bumana, su riqueza y generosidad. Cultivemos la floresta, disfrutemos de sus fragancias y de sus múltiples sabores, pero no olvidemos la semejanza esencial que une por la raíz el sentido comuin de tanta pluralidad de formas y matices $^{2}$. Savater habla de las diferencias culturales que deberían potenciar los diversos espacios geográficos manteniendo, no obstante, la raíz común de pertenecientes a la misma "humanidad". Nosotros desearíamos aplicarlo a la necesi-

1. Ley de Prevención de Riesgos Laborales. Ley 31/1995, de 8 de noviembre. B.O.E. ñ $^{\circ} 269$; đè 10 de noviembre.

2. SAVATER, Fernando: El valor de educar Ed. Ariel. Barcelona, 1997. RESOLUCION de 7 de septiembre de 1994 de la Secretaria de Estado de Educación. 
dad de una cultura (tal vez ésta con mayúscula) capaz de determinar (aunque no nos acabe de gustar la palabra), actuaciones concretas, respuestas concretas de manera universal. Por decirlo en otras palabras: la "cultura de prevención" debería quedar inmersa en la Cultura. No existe una cultura específica, en este caso, que condicione (tal vez esta palabra es aún peor) la protección de la vida, la necesidad de evitar accidentes y enfermedades; estas respuestas pertenecen a la Cultura de "raíz" por usar la metáfora de Savater. Son las "culturas" de la Cultura.

Cuando la Ley de Prevención habla de "cultura" y hace referencia al marco educativo (a todos los niveles) está hablando de la Cultura y, tal vez, sobre el adjetivo específico. Así lo entendemos nosotros, especialmente si complementamos el texto citado de la Ley con otro perteneciente a la Resolución de 7 de septiembre de 1994 relativo a la educación en valores. Dice dicho texto: El sistema educativo tiene entre sus finalidades proporcionar a los niños y jóvenes una formacion que favorezca todos los aspectos de su desarrollo, y que no puede considerarse completa y de calidad si no incluye la conformacion de un conjunto de valores que no siempre se adquieren de manera espontánea. (...) se ban ido delimitando un conjunto de temas que recogen los contenidos educativos relacionados con cada uno de esos ámbitos que junto a la educación moral y cívica, son: la educación para la paz, la educación para la igualdad de oportunidades entre los sexos, la educacion ambiental, la educación sexual, la educación para la salud, la educación del consumidor y la educación vial 3 .

No hablamos de "cultura vial" o de "cultura sexual" (si bien es evidente que las prácticas de la sexualidad varían notablemente de un lugar a otro), no hablamos de "cultura del consumidor", hablamos de Cultura. La suma de las culturas que determinan la forma de ser, de estar y de interpretar el mundo y la vida de un determinado colectivo. Es evidente que esta Cultura suma, que esta Cultura de raíz difiere de un espacio geográfico a otro, faltaría más. La universalización a la que hacemos referencia es una universalización localizable (valga la contradicción), hace referencia a grupos humanos (grandes grupos) que, por tradición e historia han mantenido durante los tiempos similitudes de base, de raíz. Pero esta "suma" de culturas genera (y es lo que nos interesa) una Cultura única, no parcializada en "capítulos" temáticos. Hace tiempo, incluso en el área de la salud, se hablaba de salud laboral; salud en el ocio, salud familiar, etc. como si la salud no fuera única. Estas matizaciones hacían referencia a los lugares o actividades en los que tal salud podía perderse, pero notemos que al hablar de la Cultura raíz estamos hablando,

3. Por la que se dan orientaciones para el desarrollo de la educación en valores en las actividades educativas de los centros docentes. B.O.E. de 23 septiembre 1994. 
por poner otra metáfora y no ser menos que Savater, del sulfato de hierro, que no es ni azufre ni hierro ni tiene las propiedades de los dos elementos, tiene unas propiedades nuevas, integradoras e inseparables, determina una nueva manera de comportarse intrínseca producto de la aparición de una sustancia diferente.

Los valores, a los que hace referencia la Resolución citada, se integran, crean una aleación determinante de la Cultura. El problema fundamental está en la calidad de los elementos (culturas) integrados. Tan cultura es que un grupo favorezca la salud de sus integrantes como que un grupo la desprecie sistemáticamente. Es decir: tan respuesta colectiva es una cosa como otra, tanto pertenece a la forma de interpretar la realidad una cosa como la otra; la "cultura" no es una materialidad, es una forma de actuar sistemática y general de un colectivo. Por ello decimos que lo importante en este sulfato de hierro es la calidad de los productos y la "orientación" de los mismos.

2. Hablar para "SER". Hablamos lo que somos Y NOS hacemos hablando. Se HABLA DE MUCHAS MANERAS, NO SIEMPRE CON "PALABRAS".

Una cultura se elabora, por decirlo de alguna manera, a partir de respuestas repetitivas sobre un objeto externo, interpretaciones constantes sobre la misma realidad, interpretaciones en el mismo sentido, respuestas al mundo exterior dadas siempre en similar sentido y que resultan gratificantes para el grupo dado que cubre algún aspecto de dicha realidad. Hablamos del conjunto de interpretacionesrespuestas que los elementos de un grupo dan de forma similar referidas a un aspecto $u$ objeto del entorno (físico o no). Lo curioso de esto es que dicha interpretación se da a través de signos (que pueden ser palabras o no). El grupo crea la realidad que le envuelve a partir de hablar de ella. Tomamos posesión de la realidad al hablarla, dado que los signos que la representan son los únicos "mecanismos" que nos permiten pensar, establecer relaciones entre las cosas, adjetivarlas, cuantificarlas y, especialmente, valorarlas en relación a nuestros deseos y necesidades. Dice Victoria Camps al hablar del lenguaje y su "forma de vida": Aprender a bablar es aprender a comportarse como un ser bumano: es sujetarse a unas normas no sólo gramaticales y semánticas, sino psicológicas, lógicas, epistemológicas, pragmáticas y socioculturales. Junto al vocabulario y a la sintaxis, el niño se habituia a unas actitudes y formas de pensar ${ }^{4}$.

4. CAMPS, Victoria: Pragmática del lenguaje y filosofia analítica Ediciones Península: Bäreelona, 1976. 
Quiere esto decir que no hay cultura sin "habla", sin capacidad de significación de la realidad y, probablemente, sin capacidad de transmisión de la misma, de comunicación entre los elementos del grupo. Toda comunicación implica un compromiso y, por ende, define la relación. Esta es otra manera de decir que una comunicación no sólo transmite información sino que, al mismo tiempo, impone conductas $^{5}$. Esta frase es de Watzlawick (uno de los principales integrantes de la llamada "escuela" de Palo Alto). Ello quiere decir que el conjunto de informaciones "habladas" (transmitidas a partir de signos y también de señales), no sólo hacen referencia a la descripción de la realidad (sea del tipo que sea), sino que ellas crean la modalidad interpretativa. Bateson, padre de la citada "escuela" de Palo Alto, matiza los aspectos referenciales y los aspectos conativos del mensaje. Esto es aquella información transmitida, el contenido semántico de los signos (referencial) y la manera en que dicha información debe entenderse (conativo). Esta última representaría la interpretación que el grupo concreto hace de determinada realidad. Quiere decir 'que un "objeto" puede pertenecer a la realidad grupal, puede ser "comunicado", transmitido a partir de signos y, como tal, correr en el habla cotidiana de la comunidad; pero esa utilización es imposible hacerla sin los aspectos conativos del signo trasmitido, sin la interpretación que de ellos hacemos. Ello supone "cargar" el signo (lo que es cargar la realidad) de unos aspectos en principio fuera de la realidad objetiva para convertir dicho objeto siempre en una interpretación del mismo y, en consecuencia, en una visión estrictamente subjetiva de la realidad. Los signos implican la relación que establezco con la realidad que representan (el aspecto conativo de signo).

Desde el plano lingüístico, la matización de las dos capacidades del signo puede asociarse a lo que Bernhard Badura denominó las dos "articulaciones" del mensaje: la que se produce a nivel semántico, de manera que cada grupo social dispone de los signos que precisa para transmitirse la realidad y sus aspectos y la articulación que se produce en la forma de dicho mensaje, de dicho signo. Es en esta segunda posibilidad en la que se dan los aspectos referenciales de la realidad y de los elementos que la transmiten. Quiere decir que las cosas pueden decirse de muchas maneras y es en la forma en la que se halla la decisión personal de interpretarlas (valorarlas) de una manera u otra. La "forma" de los signos representa un verdadero contenido, una verdadera experiencia de la realidad, dado que es, nada menos, que la valoración que el individuo o el grupo da a la realidad.

5. WATZLAWICK, Paul y otros: Cambio. Ed. Herder Barcelona, 1986. 
Ello puede llevarnos a la consideración elemental de que no por mucho "citar" palabras (accidente, enfèrmedad, prevención, seguridad, trabajo, salud, etc.), lleguemos a incorporar en la raíz cultural del grupo la "intencionalidad" deseada. Dicha intencionalidad, lo que convertirá en operativas (por usar ese extraño término) las palabras, está en la forma de las mismas, en la manera de transmitirse y, sobre todo, en la carga-valor que le proporcionemos. Dicho de forma más elemental: una cosa es hablar por hablar, otra muy diferente bablar con una intencionalidad concreta. Puede que la intencionalidad del mensaje sea, por otra parte, algo absolutamente propio de él, es decir: que no pueda entenderse un mensaje sin una intencionalidad. Repetir una palabra continuamente puede que tenga una intención concreta, precisamente contraria a lo que hubiéramos deseado. La "experiencia" que supone la transmisión de un mensaje no es, por lo tanto, el propio mensaje, sino su intencionalidad. Anné Linder, fundadora de New York Training Institute NPL, escribe una frase que puede ser el resumen de lo dicho: El lenguaje no es la experiencia, pero el lenguaje puede generar experiencia ${ }^{6}$.

Es en este sentido, relacionado con la intencionalidad del mensaje, en el que desearíamos que los términos (signos, palabras o no) transmitidos, "enunciados" generar la "realidad" social que deseamos en el campo de la prevención de riesgos laborales.

3. QUIEN NO "HABLA" NO CREA SU REALIDAD. COMUNICACIÓN Y REAIDAD. "La REALIDAD Y EL DESEO" NO ES ÚNICAMENTE POESfA. CERNUDA Y LOS "MAPAS" DE LA REALIDAD. QUIEN NO TIENE "MAPA" SE PIERDE EN LA JUNGLA DE LOS SONIDOS

Hablar, como decíamos anteriormente, no supone en exclusiva la transmisión de palabras, supone toda comunicación de signos y señales a los que un determinado grupo atribuye un concreto contenido y una intencionalidad.

Es evidente que las palabras no son la realidad, como también es evidente que no disponemos de otro mecanismo para transmitimos esa realidad que convertirla ("reducirla") a signos o representaciones que aludan a ella. El mapa de Texas no es Texas decia Noam Chomsky (y la expresión se convirtió en el eslogan de los autores de la Programación Neurolingüística PNL). Pero para desplazarnos hacia Texas, si desconocemos el camino, necesitamos de un mapa en el que se nos represente la ciudad y la manera de llegar a ella. Mapa que no tiene porque ser una materialización gráfica, puede tratarse de una explicación oral, lo que incide aún más en la necesidad de trasmitirnos la realidad por mecanismos que no son dicha realidad pero que la generan.

6. LINDEN, Anné: Ejercitar la mente. PNL para una vida mejor. Paidós. 
Ello implica, por así llamarlo, la "existencia" de dos realidades: una material (probablemente inaccesible a nosotros) y otra "virtual" absolutamente subjetiva que, con el intento de reproducir la primera lo que hace en la práctica es crear una nueva realidad, la mía, la del grupo, la "cultural".

Cernuda hablaba de la realidad y el deseo. La poesía ha sido desde siempre la fórmula comunicativa más cercana a la realidad, en tanto es la subjetivación última de la realidad y no se esconde de ello sino que pertenece a su misma esencia. La realidad y el deseo son las dos caras de la misma moneda. La realidad es una y el deseo es la adaptación de dicha realidad a mis necesidades e intereses. Por ello, la pregunta (en mucho casos pero en el caso concreto de la prevención), podría ser: ¿Cual es nuestro deseo de prevención? ¿Cual es la realidad grupal (no hablamos de objetividad) que desea nuestro colectivo referida al término prevención? ¿El deseo (la intencionalidad de nuestras palabras) es realmente que la salud-vida pertenezca a la raiz cultural de nuestro colectivo? ¿Existen datos que nos permitan sospechar que nuestra colectividad no desea que en la Cultura de grupo figuren los datos (las intencionalidades) propias del eje salud-vida? ¿Podría ocurrir que se promoviera una "cultura de prevención" propia de "hojas y flores" (en metáfora de Savater) pero no de "raíz" (aun al margen de nuestra intencionalidad y sin ser conscientes de ello)?

Hablar es ser y generar realidad (por lo menos la deseada) pero, como hemos visto, para que dicha realidad forme parte de la esencia básica de nuestra cultura $y$, en consecuencia, potencie y oriente nuestras respuestas frente a lo externo, debe quedar impregnada de intencionalidad. La palabra no basta, es necesario acudir a las intenciones profundas que las palabras transmiten como elaboradoras de la realidad deseada.

Por supuesto que determinados aspectos "objetivos" (Castejón, Castellá) ${ }^{7}$ condicionan o pueden condicionar el accidente (al fin y al cabo, dicho aspectos pertenecen también a la cultura del grupo); aspectos como el sistema de control de cumplimiento de la Ley, sistema de aseguramiento, ciclo económico por el que atraviesa el colectivo, necesaria formación de los trabajadores, rotación en los puestos de trabajo (trabajadores de ETT), etc. Es evidente que estos aspectos "organizativos" (en el sentido en que es el grupo quien "organiza" determinada variable 'de su realidad), influyen en la interpretación que cada uno de los elementos realiza respecto del objeto externo. No obstante, y desde la óptica del lingüista que analiza la formación de una cultura profunda a partir de los deseos expresados por los

7. CASTEJÓN, Emilio y CASTELLÁ, José Luis: "Accidentalidad laboral: mejoramos aunque no lo pareżca". Rev. Prevención, trabajo y salud. INSHT. (Próxima aparición). "Accidentes, empleo, carga de trabajo y peligrosidad del trabaj" Rev. Prevención, trabajo y salud. INSHT. No 1.1999. 
miembros del grupo, no dejan de ser aspectos circunstanciales. Todos sabemos que no es posible el cumplimiento "exacto" de una ley desde la "organización" de la misma. El cumplimiento de algo es, ante todo, la respuesta que una persona o colectivo dan a ese "algo" no por imperativo externo o única forma de actuar sino por "cumplimiento" de las reglas culturales intrínsecas que lo determinan. La prueba de dicha respuesta (el "sentido" de la misma) podemos apreciarla cuando a un individuo del grupo se le ofrecen dos alternativas opuestas al mismo objeto. Ganar más dinero o trabajar seguro, exponerme a un riesgo o trabajar menos tiempo, evitar problemas de espalda o manejar las cargas más "fácilmente". Los psicólogos hablan de respuestas generales y respuestas concreto-personales. Por las primeras se entienden esas respuestas "teóricas" (valga la expresión para entendernos) que damos ante un hecho externo bien porque la colectividad las ha asumido superficialmente como respuesta de "primera articulación" (sin implicación personal en ellas), bien porque "no me queda más remedio" (lo cual en ocasiones no es malo). Por respuestas concreto-personales entendemos la respuesta específica de un elemento o de un grupo, motivada por el deseo intrínseco (consciente o no) de actuar de aquella manera dado que es la forma "natural" de actuación. En este segundo caso hablaríamos de conducta determinada (en lo que cabe y sin negar ninguna posibilidad de conciencia personal), por la Cultura del grupo.

La respuesta general puede manifestarse a través de expresiones que valoran positivamente la prevención (normalmente nadie asegura "en serio" que la utilización de medidas preventivas sea "mala" o nadie acepta con naturalidad que aєcidentarse sea positivo, si bien en este aspecto podríamos hablar de culturas de la "fatalidad" que rozan dicha visión. Normalmente no suele ocurrir así.). Estamos ante respuestas generales pero ellas, y aquí intervienen las respuestas concreto-personales, no garantizan que yo, desde mi marco cultural, actúe de forma contraria despreciando cualquier protección o ignorando la propia salud. Por supuesto que ante una respuesta "cultural" negativa puedo establecer una serie de mecanismos que la modifiquen, mecanismos de organización de la propia sociedad que impidan tales respuestas; a la larga es evidente que no podré mantenerlas, que no podré "controlar" todas las variables que inciden sobre una conducta.

Stephen Covey $^{8}$ apunta alguna consideración que puede resultarnos aútil en este apartado. Supone Covey que las organizaciones (los grupos) deberían disponer de unos principios capaces de determinar, hasta donde sea posible, lá conducta de les elementos, en el sentido en el que no es necesario establecer "normas" eoncretas de actuación porque dichas normas pertenecen al substrato de la colectividad. Esto

8. COVEY, Stephen: Preparando el futuro. Ediciones Gestión 2000. Barcelona, 1997: 
es propiamente la Cultura. Covey, que apunta lo dicho haciendo referencia a lo que él denomina la "Cultura de Alta Confianza", supone que existiendo dicha base normativa (principios-valores), lo que importa en conceder "confianza" a quienes forman parte del grupo. Nada ocurrirá fuera de lo previsto salvo que, incluso, la creatividad de los elementos favorecerá la puesta en práctica de dichos principios hallando nuevas posibilidades. Asegura el autor que las sociedades no deben estar infestadas de reglamentaciones y totalmente burocratizadas, pero que ello no será posible hasta que una cultura de los principios se implante plenamente y con ella la confianza de la organización hacia los organizados.

Estos "principios" forman el mapa de la realidad grupal. ¿Dónde estamos? ¿Qué deseamos? ¿Cómo interpretamos la realidad? ¿Cuales son nuestras respuestas concretas? EL mapa es la representación (la única posible) de nuestra realidad. Mapa creado por signos, por representaciones, por relaciones subjetivas de cada uno de nosotros (y de la colectividad) con el resto del grupo y con sus manifestaciones. Cuando nos hallamos inmersos en el mapa, no es necesario mayores explicaciones, ni es necesario generar micro-mapas complementarios.

San Juan de la Cruz, y regresamos a la poesía, decía: Ya por aqui no bay camino, porque para el justo no bay ley, él para si se es ley.

\section{4. ¿QUIEN TEME LAS PALABRAS? "NO TE LO TOLERO NI EN EL PENSAMIENTO"}

¿Quien teme a Virginia Woolf? Esto podría ser la clave, la clave de la contradicción de los mensajes. Hemos apuntado que una Cultura es un mapa, un mapa de obligadas referencias fuera de las cuales el mundo no existe, no existe porque es tan objetivo que se aleja de mí, que es absolutamente inaccesible, en consecuencia: no existe. Sólo existe aquello en lo que puedo referenciarme, y esto es el mapa de mi realidad, la de los signos. La realidad inventada de Unamuno, la única realidad posible. Toda apreciación de la realidad es una interpretación de la misma, una interpretación que surge de mi experiencia y, a su vez, crea una experiencia nueva. Si mi realidad es dar una respuesta positiva al "valor" salud, esa es la única realidad, la que ha sido generada a partir de la experiencia (experiencia simbólica, valga la primera contradicción), la que se generó en el grupo como "ley" que determina la actuación del "justo" (del que pertenece al grupo y actúa en concordancia con él). Lo alarmante, lo que los estudiosos de Palo Alto han concreta en sus numerosos trabajos es la contradicción interna en la que muchos esquemas comunicativos se hallan. Es la paradoja comunicativa. Algo así como si un mapa nos ofreciera un camino que fuera a dos ciudades diferentes, las cuales estuvieran geográficamente en lugares opuestos y distando cientos de kilómetros la una de la otra. No 
todos los caminos van a Roma sino que, por el mismo camino, puede llegarse simultáneamente a Roma y a Sevilla. Esto, que en la objetividad (incluso en la del mapa, en tanto gráfico constatable), parece imposible se hace posible en la realidad lingüística y, por tanto, en la realidad de nuestros pensamientos. No es necesario regresar a las respuestas generales y concreto-personales de las que hablábamos anteriormente. Respuestas diferentes, contradictorias incluso, a un mismo hecho externo. Frente a la aparente realidad, el ser humano puede dar respuestas diferentes habiendo recorrido el mismo camino para cada una de ellas.

Es tradicional la metáfora de Watzlawick en la que se presenta el nombramiento de "barbero del ejército" al soldado que rapa la cabeza de quienes no se la rapan por sí mismos habiendo recibido la orden y cumpliéndola todos. La única cabeza rapada por dicho barbero es la suya propia, todos son, pues, barberos o el barbero no existe. Tan "real" es considerar que cada uno de los elementos cumple los requisitos para ser barbero del ejército como suponer que no existe ninguno que pueda ser denominado barbero, propiamente dicho. ¿Quien teme las palabras? ¿Quien niega la realidad de todos o quien la acepta? ¿Qué diferencia hay en la realidad entre la expresión Cbicago es muy grande y Cbicago es trisilábica? (adaptando una nueva paradoja lingüística de Palo Alto).

Es evidente que las dos expresiones son "correctas" (son lógicas), siempre que el término "omitido" sea consecuente en cada una de ellas, es decir: siempre que supongamos el término ciudad para la primera y el término palabra para la segunda. Pero siempre estaremos interpretando la expresión a partir de supuestos que no están verbalizados, supuestos que pertenecen al receptor de la expresión, que deben estar contenidos en él. Por decirlo en otras palabras: las dos expresiones son correctas si el receptor "acierta" en la palabra omitida y la coloca en el lugar adecuado.

Esto ¿qué quiere decir exactamente en el tema que nos ocupa? Pues simplemente que cada elemento del grupo "da sentido" a las expresiones añadiendo sobre ellas ("intra" ellas sería mejor decir) aspectos subjetivos. No tiene validez (valga la palabra) si no se acompaña de un contenido introducido "libremente" por el receptor. Si no figurara, por ejemplo, el concepto "palabra" (abstracción que es muy posible se desconozca a determinadas edades), sería absolutamente imposible que la expresión "Chicago es trisilábica" tuviera sentido. Ahora no se trata más que de considerar que expresiones habituales de un colectivo y que, en la basê,, generan el sentido cultural de dicho grupo, "implicaran" conocimientos previós (èludidos de la manifestación) contradictorios para elementos diferentes. El resultado podría ser o la incomprensión o la contradicción. Analicemos, por ejempló lá expresión La seguridad es trabajo de todos. Al margen de la mayor o menor habilidad lingüística del autor para conjugar "contenidos" simultáneos en la mismà fràse 
y para jugar con ellos lo más ingeniosamente posible, es evidente que dependerá de la interpretación básica de trabajo el que la "intencionalidad" de la expresión pueda considerarse positiva o negativa (atendiendo por positivo o negativo el deseo de considerar "buena" o "mala" la seguridad en el grupo). La palabra trabajo alude a una experiencia concreta y supone la existencia de contenidos eludidos. Trabajo satisfactorio, trabajo rentable, trabajo castigo, trabajo no deseado, trabajo no hallado, etc. La adjetivación de la palabra "trabajo" está eludida en la frase pero no en la interpretación que le da (inconscientemente. lo cual es peor) el receptor. Podríamos hacer el mismo análisis del término "todos", lo cual nos llevaría a conclusiones tal vez más paradójicas si cabe. Recordemos que existe (por casualidad del destino fatal) un anuncio en la televisión que vemos parte de los españoles (anuncio institucional como el que usa la frase citada), cuyo contenido implícito (eludido) es la "maldad" del trabajo, considerado como un castigo del cual uno puede huir si le toca la lotería. Los dos anuncios ( $\mathrm{y}$ en ningún momento hacemos una crítica de "ellos, únicamente destacamos las paradojas que pueden producirse en cualquier expresión y que, y esto sí que es importante, en cualquier interpretación de la realidad), se emiten, por así decirlo, uno a continuación del otro. Es evidente que el término eludido al que hacen. fundamentalmente, referencia los dos no coincide en absoluto. Sería una paradoja (difícil de superar de ahí que no podamos criticar negativamente ninguno de los dos anuncios pero sí advertir de la situación), recibir las dos expresiones "cargando" de manera incorrecta los contenidos eludidos.

Estos contenidos eludidos subyacen en las mentes y voluntades de los elementos del grupo, no gratuitamente sino como resultado de un proceso de aprendizaje colectivo. La sociedad (este término tan amplio), ha "enseñado" el contenidos de las palabras, ha mostrado el mapa a quienes, con el tiempo, debían viajar por los caminos alli representados.

Una popular canción, entre amores y desamores, dice a modo de estribillo No te lo tolero ni en el pensamiento. La frase es curiosa y mucho más profunda de lo que parece a simple vista. El pensamiento es lo escondido, lo que es mío y no tuyo, donde, en principio, radica mi verdadera libertad. Puedo decir una cosa y no "pensarla", en el sentido de no creerla, la mente encierra la verdad, la boca transmite lá conveniencia. Pero eso no es así radicalmente. En principio el pensamiento dista mucho de ser libre, al contrario, en él se hallan el montón de condicionantes que determinan nuestra conducta; condicionantes producto del aprendizaje que hemos tenido que realizar para "estar en concordancia" con el grupo al que pertenecemos. la Cultura, propiamente dicha. Las palabras de la Cultura. Las expresiones de mi interpretación de la realidad. Ahí, en el pensamiento (valga la palabra), está nuestra realidad. Pero es que dicha realidad no puedo esconderla; me sale por los 
poros del cuerpo, por las formas que adquieren las palabras cuando debo materializarlas, lo quiera o no. Nadie puede no comunicar. La comunicación no es un acto de voluntades, es una cierta condena del hombre frente al hombre, de uno en relación a otro. Por ello no hay pensamiento escondido y yo puedo introducirme en él incluso para negar que "pienses algo". Los movimientos, las miradas, el tono de las palabras y un sinfín de indicadores cada día más conocidos y estudiados (el lenguaje tradicionalmente denominado no verbal), son los encargados de "traicionarnos" mostrando (desnudando) nuestra intimidad de pensamiento delante de todo aquel que quiere y sepa leer (propiamente leer). Por ello ni te tolero que llegues a pensar lo que no deseo. No te tolero la palabra (el signo) incluso antes de materializarse. Las palabras no son sonidos que oigo, son todo tipo de manifestación capaz de ser leído y, en consecuencia, interpretado. Y yo leo profundas contradicciones cuando hablamos de accidente, de prevención, de riesgo o de seguridad. La paradoja de Palo Alto se me evidencia cuando hallo (sin desearlo incluso) las incongruencias del pensamiento y del habla (eso que llaman los lingüistas tensión comunicativa). El mensaje no verbal, por seguir con esta nomenclatura, entra en tensión (paradoja) con el verbal. El pensamiento no dice lo que dicen las palabras sabiamente pronunciadas.

Moviéndonos siempre dentro del ámbito "cultura de la prevención", las palabras que nos están indicando al grupo la conducta esperada (precisamente la palabra prevención) no suelen estar en concordancia con el pensamiento que las enuncia. Existe en nuestra Cultura ingredientes suficientes para que el "pensamiento" vaya por una parte (y el grupo descubre la dirección aunque no sea intención de nadie comunicarla), y la "palabra enunciada" vaya por otro. Estamos andando un camino que lleva a dos ciudades diferentes, a dos conductas concretas que difieren notablemente, a una realidad y un deseo notablemente diversos.

En el tema que tratamos podemos "leer pensamientos" paradójicos del estilo ¿Qué contento estoy de que no me gusten las espinacas! Porque si me gustaran, tendria que comerlas, y las odio. Comportamientos sociales adversos nos sirven de excusa para no llevar a término, profundamente, las modificaciones culturales oportunas que nos llevaría a la prevención. iQué suerte tengo de que todo funcione tan mal, porque si funcionara bien tendría que cumplir la Ley de prevención y no me interesa nada cumplirla. Y esto vale para todos los estamentos sociales, puesto que todos dichos estamentos crean o "recrean" la Cultura constantemente. A la llamada cultura de prevención le falta una operación fundamental de lo que los teólogos denominan opus restaurationis porque la opus creationis generó una forma de hacer y de interpretar opuesta radicalmente a la esencia cultural del valor vida. 
No es extraño lo dicho si consideramos que estamos hablando desde una Cultura que ha convertido en símbolo nacional (en fiesta) el "arte" del riesgo. Nuestra Cultura se mueve constantemente en las contradicciones profundas que enfrentan la cultura "toreril" (valga la expresión) con la prevención de los riesgos y la aceptación del valor vida. Puede que esto no sea ni bueno ni malo (nada lo es si no lo referenciamos), pero está claro que las dificultades que tal contradicción conlleva explican muchos de los problemas de menosprecio a la vida.

5. ¿BAILAS O, SIMPLEMENTE, TE MUEVES? ¿HABLAMOS JUNTOS O MONOLOGAS MIENTRAS TE MIRO?

Hemos hablado anteriormente de la intencionalidad del mensaje. Dicha intencionalidad, como veíamos, es intrínseca (probablemente) al propio mensaje y se transmite, como también decíamos, a través de la "forma" que adquiere el mensaje, de la segùnda articulación del mismo. Esta forma es, por otra parte, la que nos permite "ver" el pensamiento del emisor, el real, el verdadero, matizando así el contenido puramente verbal o significativo de las palabras o expresiones. Tal vez entremos ahora en un apartado fundamental para abordar definitivamente el tema de la la "cultura preventiva" como integrante de la Cultura de un grupo. Una cosa es la intencionalidad del mensaje y otra la interpretación que el receptor hace del mismo. Esta interpretación, subjetiva y condicionada al mundo actitudinal, de creencias, de opiniones, de vivencias personales, etc. dará la versión "real" del mensaje, real para el receptor, por supuesto. Los lingüistas y psicólogos de la PNL suelen usar la siguiente expresión: El significado de su mensaje está en la reacción que provoca, sea cual sea su intención ${ }^{9}$. Esto es: en la interpretación que el receptor hace del mensaje y en la conducta que genera. Ahora bien, cabe decir que tal reacción es producto de las dos lecturas: la descodificación de la palabra a partir de su contenido normalizado (diccionario - código) y la forma de emisión, capaz de contradecir la primera, como decíamos (paradoja). No obstante, las dos lecturas están condicionadas casi por igual a variables externas. Quiero decir: cuando los colegas de la PNL hablan de la lógica subjetivación del mensaje, pueden dar a entender que cada elemento del grupo tiene una forma diferente de interpretar el mensaje recibido. Por supuesto que esto es así, pero en un porcentaje pequeño. La "parte" de mensaje que depende de mi interpretación personal es equivalente a la diferencia intrínseca que hallamos entre tú y yo. Pero quienes pertenecemos a un mismo colectivo "nos parecemos bastante" (por decirlo así) y ello implica que tam-

9. LINDEN. Obra citada. 
bién las interpretaciones sean relativamente similares. Las reacciones a un determinado mensaje suelen ser relativamente similares entre todos los elementos del grupo, otra cosa es que discrepen tales interpretaciones de la intencionalidad del emisor. Ello querría decir que, "más o menos" todos los receptores de un mismo grupo reaccionarán de la misma manera ante un estímulo comunicativo, al margen de que tal reacción sea la prevista o no por el emisor. No se trata de uniformizar radicalmente las reacciones de los elementos de un grupo, se trata de aceptar (y esto es precisamente la Cultura) que la reacción grupal será homogénea (hasta cierto punto) a partir de la interpretación de un contenido y una forma concretos. No existen tantas respuestas como personas. Pueden haber matices (incluso casos que salgan claramente de la "norma"), pero no por ello podemos decir que ante un estímulo doscientas personas pertenecientes al mismo pueblo actúen de forma radicalmente diferente, en principio porque, probablemente, no existan doscientas respuestas diferentes a un único estímulo.

¿Qué implica esto? Esto implica que el colectivo requiere de mensajes, en el sentido más completo de la palabra, que sigan el paso (otra expresión de la PNL) de la colectividad. Los citados autores utilizan el término bailar. Emisor y receptor deben bailar. Y deben hacerlo armónicamente, con deseo de hacerlo, con "gracia", adecuándose continuamente el uno al otro. Los mensajes emitidos (la realidad comunicada) deben estar en armonía con la interpretación que el colectivo hará de ellos. No pueden hallarse fisuras, ni contradicciones, ni mentiras (que serán descubiertas tarde o temprano). Debemos bailar armoniosamente todos hacia el objetivo de incorporar en la Cultura del grupo, en nuestra forma de ser colectiva, los valores que deseamos. La dificultad de incorporar la cultura de prevención, como otras, a la Cultura es la irregularidad del baile, la "patosidad" (permítaseme tan vulgar expresión) de los danzantes, el desconocimiento del paso de la pareja, el importarme un higo (en castiza expresión de Santa Teresa) cómo baila el otro, que necesidades tiene, que ritmo desea llevar, cómo está interpretando mis susurrantes palabras. Simplemente nos movemos, sin un plan preconcebido, sin objetivos concretos que sean producto de la investigación, sin mecanismos armoniosos que, lentamente, produzcan los cambios deseados.

Cuando tratamos de enseñar a los profesionales las pocas técnicas de las que disponemos para "hacer" transversalidad en la escuela, nos percatamos que el aspecto más importante para que un objetivo oculto se consiga es que el profesor (el emisor) se lo crea. Si no se lo cree (Cultura), si no pertenece al conjunto de normas e interpretaciones que le hacen ser de esta manera en concreto, simplemente: se mueve frente a los alumnos, pero no baila con ellos. ¿Qué pensaríamos del profesional de la enseñanza que intenta transmitir el objetivo oculto referente a la igualdad de oportunidades entre hombres y mujeres y él mismo no lo practicara? equdría 
un profesor o profesora hacer reaccionar a sus alumnos y alumnas si él o ella parten de no creerse lo que transmiten? En principio supondríamos que sí, en la práctica (y debido a que en comunicación es imposible mentir), absolutamente no. Tarde o temprano los alumnos descubrirían que un señor o señora se ha estado moviendo delante de ellos, pero que jamás ha bailado, simplemente porque tal baile no le importaba o, y éste es el detalle fundamental, el baile (ése en concreto) no estaba en los esquemas de su conducta "profunda".

Establecer un baile "operativo", implica lo que se denomina orientación bacia el otro. Dice Anné Linden La orientación bacia el otro implica prestar atención a la otra persona, y a las señales $e$ indicios que esa persona emite, indicadores conductuales que indican que se está recibiendo el mensaje. ¿̇stá él o ella entendiendo su mensaje? ¿Presenta usted lo que tiene que decir de una forma que tiene sentido? ¿Cómo lo sabe? ¿Da la otra persona señales de que ve lo que usted quiere decir? ¿En que sintoniza con lo que usted dice?" "Coge" sus razonamientos?10. Si todo ello no se produce, probablemente no estamos bailando con la pareja, simplemente nos movemos y... en ese momento no podemos esperar que la reacción (respuesta) a nuestro mensaje sea el deseado, el que deseamos como respuesta más o menos universal del colectivo. Respuesta que, por otra parte ( $\mathrm{y}$ ya fue destacado más arriba) no espero que se dé superficialmente, como una mera aceptación "teórica", deseo que se dé claramente en cada uno de los miembros.

¿Hablamos juntos? ¿Estamos creando una cultura de prevención en la que participamos todos? ¿Emitimos los mensajes oportunos a una modificación profunda de la Cultura? $\mathrm{O}$, por el contrario, los intereses de unos van en un sentido y los de los otros en otro. Es evidente que el hecho de replantearse en profundidad una respuesta cultural supone una gran dificultad. Estamos diciendo, nada menos, que la manera de interpretar una cosa (interpretación colectiva) debe ser modificada por otra nueva interpretación que, en estos momentos, nos resulta más efectiva. Todos cometemos errores, todos perdemos naves (incluso Colón perdió parte de las suyas como reza una popular frase), lo que parece inviable es que los errores se mantengan a lo largo de los tiempos y que la contradicción de base no se intente superar, salvo que intereses más recónditos nieguen el enfrentarse abiertamente con el problema. En una polémica entre Umberto Eco y Adriano Sofri (que ha dado lugar al libro de Antonio Tabucchi La gastritis de Platón, el primero de los citados, ante la inoperancia de los intelectuales por provocar verdaderos cambios culturales en la sociedad, se planteaba que: (...) en vez de malgastar esfuerzos en reeducar a alcaldes impermeables a los más elementales razonamientos, lo que debe bacer el intelectual es escribir manuales de educación civica para que los futuros

10. LINDEN. Obra citada. 
nietos de tales alcaldes aprendan el civismo del que carecen sus abuelos ${ }^{11}$. La frase contiene dos aspectos importantes a destacar en el objetivo que perseguimos: en primer lugar la idea de que las enseñanzas que deben producir cambios culturales deben partir de algún sitio, sean intelectuales o técnicos de seguridad e higiene y, en segundo lugar, que es mucho más práctico formar a los niños y adolescentes: que a quienes ya han madurado (en el peor sentido de la palabra) en una "cultura" hecha de reacciones contradictorias y a los que va a resultar muy difícil acceder. La primera observación podría resultar contradictoria a la idea de que una cultura la "hacemos todos"; puede ser cierto, no obstante, el papel tanto formativo como "directivo" de los profesionales no puede ser marginado. Una vez se ba seguido el paso de la persona está preparado para bacerle de guía - dice, de nuevo, Année Linden - hacia algo o algún otro lugar, pensamiento o conducta. Llevar a alguien a un lenguaje (subrayamos la palabra "lenguaje"), o postura o tempo diferentes puede cambiar su punto de vista. Y la nueva perspectiva puede comportar nuevas opciones, posibilidades, y creatividad. Bailar, bailar guiando, interviniendo activamente, sinceramente, aportando las palabras/contenidos que modificarán las conductas del grupo (de todo el grupo). Pero... para ello es necesario el deseo.

Lamentablemente, los ciudadanos de nuestras "culturas" sólo hablan de "bailar" cuando, como dice la cancioncilla, el torero y la muleta caminan al mismo son.

$Y$ al final, como nadie puede engañar a nadie "profundamente", nos vamos haciendo conscientes (paulatinamente) de que la falta de cultura de prevención es conocida por todos, controlada por todos y que todos sabemos como solucionar el problema (cada uno con nuestras razones y nuestras experiencias personales); sigue faltando el deseo, porque sin él disponemos de una "cultura de prevención" que, por una razón $u$ otra debe interesarnos también a todos (excepto a quien muere que, en ese momento por lo menos, le han fallado las conductas que, pudiera ser, él mismo daba en favor de la falta de prevención). Tal como decíamos anteriormente, no es que no tengamos una cultura de prevención (entendiendo éstà como una manera concreta de interpretar los hechos), lo que ocurre es que nuestra cultura de prevención no concuerda con la protección de la vida, con el valor (que tampoco tenemos, lógicamente) "protección de la vida". Adaptando una nueva frase célebre, podríamos decir que cada sociedad tiene la cultura que se merece (o que desea, por una razón u otra, consciente o inconscientemente).

11. TABUCCHI, Antönio: La gastritìs de Platön. Anagrama. Barcelona; 1999. 


\section{6. ¿PERO... DE QUÉ CULTURA Hablamos? "ENTRE todos lo haremos TOdo”}

Si después de lo dicho, amable lector, aún no es capaz de identificar claramente a qué cultura nos referimos, le ocurre algo similar a lo que le acontece al autor de este artículo. Pero, probablemente, no por falta de atención de ninguno de nosotros, sino por la dificultad intrínseca de definir el concepto de "cultura" y hallar los motivos por los que se hace tan difícil conseguir la famosa "cultura de prevención".

Recapitulando en tres frases, podríamos decir: no existen "culturas", existe una Cultura; la Cultura se "hace" a partir de los mensajes que nos transmitimos los unos a los otros sobre determinado contenido; la Cultura "determina" el comportamiento de los elementos (hasta cierto punto) y esta determinación debería implicar respuestas concretas de las personas. Podríamos añadir que esto tiene un signo u otro dependiendo de profundas raíces cuya modificación resulta siempre difícil, sobre todo si tales modificaciones se pretenden ( $\mathrm{y}$ a mi modo de ver este es el gran "secreto") a partir de mensajes contradictorios.

Siguiendo un poco más en la reflexión que iniciamos hace un rato, sumerjámonos en los geniales versos de Alain Bosquet (pertenecientes, por cierto, al poema Lucidité): (...) Est-il fable plus douce / que cette intelligence, avec ses fleurs de plomb, / qui va de mot en mot se perdre dans le sables? Ello para introducirnos en una nueva metáfora/realidad/ejemplo (combinación de materias probablemente incombinables). Mientras escribo esto (reflexión tras reflexión), un partido político propone una honorable acción cívica (y no hay el más mínimo toque de ironía en ello, en todo caso existe un deseo de que consiga sus propósitos porque ello colaboraría a entender lo de la "cultura de prevención"), consistente en que ningún ciudadano compre productos en cuya elaboración hayan intervenido menores de edad. Loable actitud, generosa propuesta. Lo malo es que ello sugiere ciertas proposiciones y ciertas preguntas, que condicionan el objetivo. En las que yo "caigo" son: 1) Que "todos" lo sepamos (dudo de que tal propuesta sea conocida por un porcentaje de la población que supere el $10 \%$, tal vez incluso exagerando mucho). 2) Si no se conoce, es porque no se ha hablado de ello, porque no pertenece al mensaje o a los mensajes que fluyen "por" el habla del grupo social; esto es: que es una idea que parte de alguien y no llega a los demás. 3) No se han previsto los mecanismos para que el mensaje se "difunda" (divulgación, difusión, publicidad), o... tal vez estos mecanismos no existen o no están interesados en la difusión. 4) ¿Qué ocurriría si los productos elaborados por menores fueran más baratos que los demás? ¿La respuesta concreto-personal sería "no obstante no los compro? 5) ¿Duda alguien de que el país entero, interrogado sobre la bondad o no del trabajo de menores, respondiera que hacerlos trabajar, en lugar de la regular 
asistencia a la escuela, es una injusticia, una barbaridad y una vergüenza para el siglo XXI? (Diferencia entre respuesta general y respuesta personal). 6) ¿Quiénes deben salir ganado haciendo trabajar a los menores? Es de suponer que no trabajan ganando más que un adulto. 7) ¿Quién modificará la hipócrita cultura que mantiene las dos respuestas simultáneamente? (La contradicción, la paradoja). 8) ¿Por qué la laudable idea no se hace machacona en una sociedad civilizada y sólo surge ante unas elecciones? 9) ¿Sabíamos todos que los menores trabajan en lugar de estar escolarizados? ¿Da igual que los menores sean de nuestro país o sean de lejanos y exóticos lugares? ¿Qué nos importa lo que ocurre en otras "culturas"? ¿No pertenece, precisamente, a la Cultura de esos exóticos países el que trabajen los niños? ¿No es mejor trabajar, aunque se sea menor, que morir de hambre?

Pregunta final para iniciados: ¿Conseguirá el partido político que la población entera deje de comprar productos elaborados por menores? ¿Conseguirá la loable reconversión de una respuesta que, por otra parte, no impide el sueño a nadie? ¿Se incorporará en la Cultura el desprecio profundo por todo producto elaborado por menores?

Lo más probable es que, traduciendo a Bosquet, nuestra inteligencia, de un vocablo en otro se pierde en las arenas.

La idea, sin duda progresista, del partido político aludido, es parecida al intento de incorporar en la Cultura de nuestro grupo social el "desprecio" profundo por la pérdida de la salud en el trabajo. No trabajaremos, no compraremos productos, marginaremos, etc. a toda empresa en cuyo proceso productivo se produzcan accidentes, a toda empresa que no incorpore (en profundidad) el "deseo" de vida.

Pero los grandes deseos no son simples palabras (veamos que he dicho "simples" palabras, lo que es lo mismo que decir "palabras vacías" o "anti-palabras"), son palabras con verdadero contenido, capaces de generar Cultura. No deja de ser curioso que esto de lo que hablamos, que no es de otra cosa que crear valores ( $\odot$ recrear valores) que modifiquen sustancialmente la relación entre las personas, coincide con la manifestación de Naciones Unidas declarando el año 2000 comø Año Internacional de la Cultura de la Paz. Definen dicha Cultura de la Paz con los términos conjunto de valores, actitudes y comportamientos basados en el respeto a la vida.

Es interesante destacar las "palabras" (las palabras-realidad): valores, actitudes y comportamientos. No sé si los organizadores se han dado cuenta del orden lógico de las mismas, forman parte de una estructura (en ningún momento son sinónimos); lo fundamental es la existencia del valor, y ello es la cultura profunda, la cültura raíz, la Cultura; a partir de dicho valor se generan actitudees, predisposiciones, formas de responder concreto-personales; todo el mundo de las respuestas quie, individualmente, damos a los objetos externos $y$, finalmente, dichas actitudes 
"determinan" los comportamientos de las personas, lo que "hacen" dichas personas en el conjunto de la sociedad, en la relación que establecen con los semejantes y con el entorno material. Los comportamientos, en expresión pedagógica, son los procedimientos de que dispone la persona para hacer, para manifestarse hacia la realidad. Es un esquema perfecto: de la Cultura a los procedimientos de actuación.

Es evidente que a esa Cultura se llega entre todos. La popular expresión "entre todos lo haremos todo" adquiere su sentido profundo en la "elaboración" de una Cultura. No obstante, los "pensadores", los "dirigentes", tal vez los "intelectuales" (esos de los que dice Umberto Eco que su primer deber es permanecer callados cuando no sirven para nada), tal vez los movimientos sociales o de trabajadores, deberian "tomar partido" decididamente hacia el logro de la Cultura de la Paz. Cuando todos ellos bablen, y ya hemos escrito suficiente sobre el valor de la palabra, probablemente, los demás, todos empezaremos a hacer nuestras las propuestas culturales. Por suerte, existen personas que observan la realidad con mayor lucidez (y, sobre todo, mayor credibilidad y capacidad de difusión), y son capaces de àportar los datos necesarios para modificarla. Esperamos de ellos palabras creadoras.

Es interesante, en este sentido (en la "popularización" de un término, de una actitud, por parte de los intelectuales, los que escriben artículos "de opinión" de los diarios y revistas), el comentario de Josep $M$. Loperena aparecido en $E l$ Periódico el 6 de octubre del 99. Dice el autor, refiriéndose a un caso de malos tratos a los niños (tema en el que también la Cultura debe dictar sus normas), Se bace imprescindible una información, exhaustiva y detallada. de cada caso de tal manera que llegue a provocar la náusea. Esto es: es necesario hacer público con las palabras, con la realidad-palabra, cotidianas la realidad que deseamos modificar, hasta que, reconvirtiendo la actitud, se origine una respuesta automática (cultural) frente a un hecho que perturbe un valor social, civilizadamente adquirido. La sociedad en la que vivimos ha tardado muchos siglos en otorgarse una serie de valores que manifiestan su civismo (civismo del que tratan Camps y Giner en su popular Manual de civismo), valores que, por desgracia no han pasado plenamente a la Cultura y subyacen en las teorías en muchas ocasiones, no obstante sería de lamentar que no insistiéramos en ellos hasta incorporarlos plenamente a nuestra "civilización" (civilización como cúmulo de respuestas deseadas para el buen funcionamiento del grupo). To change attitudes by changing names dice Stevenson. 
7. EL BAILE DE LOS PRONOMBRES PERSONALES. TODOS FORMAMOS A TODOS.

Pare USTEd la REPRODUGCión PORQUE DE lo CONTRARIO NO SALDREMOS NUNCA DEE MISMO SITIO. LA RANA QUE PIERDE LA CONFLANZA, MUERE AHOGADA

Watzlawick en su Teoría de la comunicación bumana ${ }^{12}$ cita un fragmento de Lewis Carol para ejemplificar el baile de pronombres en el que nos hallamos cuando establecemos un proceso comunicativo, atendiendo a que el "envolvimiento" aparentemente ilógico de las expresiones pueden llevar al emisor y al receptor a una situación extraña de relación personal que, no obstante la extrañeza, determina la situación entre los dos y el propio contenido comunicativo. Dice Carol: Ellos me dijeron que estuviste con ella y que me mencionaste a él; ella dio de mí buenas referencias, pero dijo que no sé nadar. Él les avisó que yo no babia ido (nosotros sabiamos que no era verdad) si ella bubiera llevado el asunto adelante, ¿qué sería de ti?

El juego de Carol es el juego de la realidad cotidiana. No estamos solos. Nos citamos, nos agredimos, nos amamos y, en conclusión, el juego de los pronombres crea un conjunto (la famosa nube o mosaico de los mensajes) de signos que hacen constante referencia a lo que pensamos, creemos ser, interpretamos de los demás, etc. Pero siempre hablamos de nosotros mismos, en tanto no tenemos más niveles de percepción de la supuesta realidad. Lo interesante de todo ello es que, envueltos en pronombres, creamos la citada Cultura y la transmitimos a nuestros sucesores, a los niños y niñas que se incorporan a la sociedad. No transmitimos "realidades", trasmitimos subjetividades que para más inri hablan de nosotros y de la relación que mantenemos con los demás. Aun el tema más objetivo no puede ser transmitido a otra persona sin que la interpretación que de ella tenemos intervenga en la transmisión y, con ella, en el propio sentido del objeto.

Las relaciones establecidas, y sus consecuentes manifestaciones comunicativas, forman un sistema en el que la retroalimentación constante es la que caracteriza el resultado final. Como dice Watzlawick la interacción comunicativa no es sumati$v a$, en el sentido en que forma un nuevo "producto" que no puede identificarse como simple suma de elementos individualizables (recordemos el sulfato de hierro del que hablábamos anteriormente). Imaginemos pues, un conjunto de pronombres entrelazándose entre ellos, formando una amalgama y, lo que en este caso nos interesa, "reproduciéndose" constantemente en los nuevos elementos llegados al conjunto.

12. WATZLAWICK, Paul: Teoría de la comunicación bumana. Herder. Barcelona, 1987. 
Hay una frase brillante de Pierre Bourdieu y Jean-Claude Passeron perteneciente a la obra La reproduction que dice: Toda acción pedagógica es objetivamente una violencia simbólica en tanto que es una imposición, por un poder arbitrario, de una cultura arbitraria ${ }^{13}$. Una violencia de las palabras, de los signos, de los pronombres a través de los que nos comunicamos. Esta Cultura (arbitraria, por supuesto, lo cual no es ni positivo ni negativo dado que una forma de ser y estar es siempre algo contingente), se reproduce de manera impositiva (tampoco hay otra manera de hacerlo) a través de la enseñanza. Los niños y niñas, a partir de una cierta capacidad de aprendizaje, tantean la "realidad-virtual" en la que nos movemos (valga la expresión), realidad generada de palabras, de interpretaciones que oyen y de observaciones que realizan (a partir también de las capacidades de observacióninterpretación que les han sido proporcionadas, al margen de la biológica capacidad natural). Dice Sebastià Serrano ${ }^{14}$. Pienso que el ser humano al nacer dispone, es innato, de una especie de algoritmo de reconocimiento de situaciones comunicativas. Este mecanismo le permite organizar el mundo de su percepción e interiorizarlo. Transforma las percepciones en conocimientos y retroalimenta los mecanismo. Continuamente se arriesga y hace experiencias a manera de predicciones. Los otros miembros de la comunidad, que lo son porque tienen una competencia comunicativa que los ba convertido en miembros, dirigen su aprendizaje sobre la base de pararles los pies ante los errores y reforzarles el valor de los éxitos. Realmente, un niño asimila la cultura tal como un cientifico consigue una buena teoría. Será buena en la medida en que las predicciones que sea capaz de bacer puedan ser verificadas, pasen la prueba de la experiencia. Un niño forma parte de una comunidad cuando sabe que una pregunta se ba de contestar, que una orden depende de quien la da para que se cumpla y que no todos pueden prometerlo todo. sabe que bay unos lugares para sentarse en clase y en la iglesia, y sabe que bay unas partes del cuerpo que no se tocan. Que se come en un lugar, en comunidad. y que se bace pipi en otro, y solo. Todo esto que sabe es su cultura. Es su competencia comunicativa. Vale la pena hacer una cita tan larga, especialmente cuando lo que dice Serrano es mucho más importante que lo que digo yo. Sebastià Serrano, por otra parte, propone un ejemplo que, subliminalmente, alude a un tipo de "cultura" que muchos hemos vivido y que deseamos olvidar (olvido que, dicho sea de paso, implica la esencia, como método, de lo que estamos contando: la manifestación ad nauseam de una forma de interpretar la vida para modificarla; el uso de unas palabras, por la vía de la ironía, para modificar una actitud).

13. BOURDIEU, Pierre y PASSERON, Jean-Claude: La reproduction. Les editions de Minuit. París, 1970.

14.SERRANO, Sebastià: Signes, llengua i cultura. Edicions 62. Barcelona 1988. 
El papel reproductor de la enseñanza parece ser importante. Incluso diría yo que resulta difícil de eludir Aunque yo pretenda que mis hijos "piensen por ellos. mismos" es evidente que la materialización de ello no dependerá de mi voluntad: sino de las manifestaciones que les transmita (volvemos de nuevo a las respuestas: concreto-personales), y que pensarán por ellos mismos en virtud de que yo lo hagá también y que el modelo presentado se reproduzca adecuadamente.

Nos enseñamos unos a otros, consciente e inconscientemente, dándonos la Cultura que, simultáneamente, estamos haciendo entre todos y de la que reproducimos la mayor parte, alterando aquellos principios que constatamos poco útiles para la "eficacia" del vivir cotidiano. Cuando hablamos de que no conseguimoś modificar la negativa cultura de prevención hacia una positiva cultura de la vida y: no integramos dicha nueva cultura en la Cultura de nuestro grupo, estamos aceptando que, sea como sea, "ya nos debe ir bien así", porque de lo contrario el grupo hubiera modificado (de forma lenta pero segura) las actitudes que producen los actos inseguros. Los unos a los otros nos hubiéramos "parado los pies" hasta conseguir la respuesta que nos hubiera sido más positiva. Entendiendo que todos colaboramos en la reinterpretación de una predisposición pero son los que ocupan lugares de mayor influencia quienes pueden acelerar el proceso. Decimos que nos enseñamos, deberíamos hablar de nos "educamos", entendiendo este término. como aquel que amalgama en su semántica el mundo de los valores y de las actitudes. Tal vez nos enseñamos muchas cosas (conocimientos y procedimientos) y nos educamos en pocas (actitudes). Dicen María Victoria Reyzábal y Ana Isabel Sanz que Mientras la enseñanza suele implicar simplemente mostrar o exponer conocimientos, principalmente de tipo conceptual o procedimental, y de carácter casi siempre científico o técnico, dirigidos a formar trabajadores más o menos cualificados, la educación abarca una actividad más compleja, que contempla el desarrollo de todas las capacidades de la persona, incluidos los valores y las actitudes, $y$ persigue preparar al individuo para la vida en sociedad 15 . Se trata pues, de educarnos convenientemente. No obstante, insistimos en lo dicho antes: no es que no. estemos "educados", es que estamos "maleducados" (valga el juego). No es que no tengamos cultura de prevención (esto sería imposible porque determinaría la no: existencia del concepto), lo que tenemos es una "mala" cultura de prevención. La educación es, precisamente, lo más reproducible socialmente, dado que no implica manifestaciones conscientes y organizadas sino que basta, como veíamos, con la simple transmisión de las palabras y el simple hecho de "vivir" en grupo. Estamos siempre moviéndonos en el mismo plano: reconvertir una cultura es modi-

15. REYZÁBAL, María Victoria y SANZ, Ana Isabel: Los ejes transversales. Aprendizajes para la uida: Editorial Escuela Española. Madrid, 1995. 
ficar, a través de la educación, actitudes (aceptar valores) que den como consecuencia la modificación de comportamientos personales, y esto realizado (asumido) en grupo, con el claro deseo de la modificación y no creando un conjunto de paradojas sociales que impidan llegar al objetivo.

Porque lo verdaderamente malo del tema es que la cultura maleducada de prevención está siendo reproducida (y además de malo es alarmante), en niños y niñas.

Es necesario salir de Java, es necesario no perder la confianza en que un valor puede ser adquirido y puede pasar, con el tiempo, a proporcionar las actitudes que deseamos. La rana que, caída en una lechera perdió la esperanza y dejó de moverse, se ahogó; mientras que la que luchó moviendo sus patas constantemente, acabó haciendo una bola de mantequilla sobre la que pudo posarse. (Según el popular cuento francés que tanto furor hace entre los compañeros de la PNL). Es necesario romper la cadena reproductora. Si no queremos que los menores trabajen, será necesario (todos) dejar de comprar productos por ellos elaborados aunque sean más baratos, aunque sean más bonitos 0 aunque creamos (hipócritamente o no) que damos trabajo a quienes se mueren de hambre. $Y$ vamos a tener que manifestar dicha voluntad a través de cada uno de nuestros actos que tengan a ver con ello (en público y en privado. En privado es donde se notan de verdad las respuestas.) Y vamos a tener que bablar (en el grupo) del tema constantemente, creando la realidad "desprecio a productos hechos por menores" (de lo que no se babla, no existe), y vamos a tener que educarnos en este deseo y educar a nuestros menores con la palabra, el gesto y la omisión. Y vamos a tener que cargar las palabras de connotaciones negativas, al hablar de ello, declarando las intenciones claras de nuestra voluntad, sin tapujos ni paradojas engañosas. Y vamos a tener que llamar al pan, pan y al vino, vino. $Y$ dar prioridad a lo primero (aunque no necesariamente en este orden. Valga el chiste absurdo de la Ley de Murphy).

El grupo debe actuar, propiamente, como grupo. No valdría en este caso el verso del Himno egipcio a Nilo Quien quiera vivir, vivirá; quien quiera morir, morirá, porque el grupo actúa como un solo individuo. Ello es dado que la Cultura es una y que condiciona la raíz de nuestras conductas. Una raíz que hemos decidido conjuntamente y que está hecha de los valores que deseamos influyan en nuestras vidas, en la relación que establecemos con los otros y con el entorno físico. Especialmente esto es válido para el mundo del trabajo. Alain Touraine ha dicho muy recientemente analizando el papel de la sociología del trabajo en la actualidad: El trabajo no es, por tanto, un elemento central de una filosofía del progreso, pero es, más que antes, una forma de resistencia a las presiones del mercado $y$ de construcción de una identidad personal y colectiva ${ }^{16}$. Una forma

16. TOURAINE, A.: De la antigua a la nueva sociologia del trabajo. Rev. Sociología del Trabajo. ST. Madrid invierno 1999. 
de hallar la identidad personal y colectiva. Esto es una Cultura, una forma de inter pretarnos y de interpretar, de entendernos a nosotros mismos tanto individual mente como en grupo.

Para esta comprensión, para hallar la identidad que deseamos (sale de nuevo ell término deseo), para no reproducir constantemente una maleducada cultura que; puede sernos práctica de inmediato pero que no deseamos para el futuro de nues: tra civilización, es necesario hacer renacer la expresión más clásica de Paulo Freire: bacemos conscientes de nuestra realidad, del objetivo que nos hemos señalado $y$ hallar el camino para conseguirlo. Una vez esto definido, es necesario no apartar nos un ápice del proyecto, aunque resulte más fácil seguir el contrario (más bara to, más rápido, más rentable) e incorporar definitivamente todo ese cúmulo dẹ "culturas" deseadas pero no vividas en la Cultura de nuestro colectivo.

\section{BiBLIOGRAFÍA}

ACEÑA, José María y otros. Didáctica de la Lengua y la Literatura. Grupo Anaya, S.A.; Madrid, 1989.

AKMAJIAN, Adrián y otros. Lingüistica: una introducción al lenguaje y la comunicación: Alianza Editorial, S.A., Madrid, 1984.

BADURA, Bernhard. Sociologia de la Comunicación. Ariel S.A., Barcelona, 1979.

BAYLON, Christian y otro. La comunicación. Ediciones Cátedra, S.A., Madrid, 1996.

BENOIT, Denis y otros. Introduction aux Sciences de l'Information et de la Communication. Les Éditions d'Organisation, París, 1995.

BERLO, David K. El Proceso de la Comunicación. Introducción a la teoría y a la prä́ctica. Editorial "El Ateneo", Buenos Aires, 1971.

BORDIEU, Pierre y otro. Le sens Commun. Les Éditions de Minuit, París, 1970.

BÜHLER, Karl. Teoría del lenguaje. Talleres Gráficos de Edic. Castilla S.A., Madrid, 1966.

CAMPS, Victoria. Pragmática del lenguaje y filosofía analítica. Ediciones 62 S.A., Barcelona, 1976.

CHOMSKY, Noam. El lenguaje y el entendimiento. Editorial Planeta - De Agostini S.A., Barcelona, 1992.

CHOMSKY, Noam. La Lingüistica Cartesiana. Editorial Seix Barral, S.A., Barcelona, 1970.

CUDICIO, Catherine. PNL et communication. La dimension créative. Les Editions: d'Organisation, París, 1991.

CUDICIO, Catherine. Maîtriser l'art de la PNL. Les Éditions d'Organisation, París, 1988.

HANDY, Charles y otros. Preparando el futuro. Ediciones Gestión 2000 S.A., Barcelona, 1997. KATZ, Jerrold J. La realidad subyacente del lenguaje y su valor filosófico. Aliańza Editorial, S.A., Madrid, 1975.

KRUSCHE, Helmut. La rana sobre la mantequilla. Editorial Sirio S.A., Málaga, 1996. 
LEHNISCH, Jean-Pierre. Maîtriser la communication dans lentreprise. Les Éditions d'Organisation, París, 1988.

LINDEN, Anné y otro. Ejercitar la mente. PNL para una vida mejor. Ediciones Paidós Ibérica S.A., Barcelona, 1999.

LLACUNA, Jaime. Modificación de conducta y comunicación. Revista "Mutual Cyclops", $\mathrm{n}^{\circ}$ 32, Barcelona, 1998.

MOHL, Alexa. El aprendiz de brujo. PNL. Editorial Sirio S.A, Madrid, 1998.

NEIGHBOUR, Roger. La consulta interior. Kluwer Academic Publishers, Barcelona, 1997.

ORGOGOZO, Isabelle. Les Paradoxes de la communication. Les Éditions d'Organisation, París, 1988.

ROGER, Natalie H. A vous de parler!. Les Éditions d'Organisation. París, 1982.

SAVATER, Fernando. El valor de educar. Editorial Ariel S.A., Barcelona, 1997.

SERRANO, Sebastià. Signes, Llengua i cultura. Edicions 62 S.A.. Barcelona, 1988.

WATZLAWICK, Paul y otros. Teoría de la comunicación bumana. Editorial Herder S.A., Barcelona, 1987.

WATZLAWICK, Paul y otros. El cambio. Editorial Herder S.A., Barcelona, 1986.

WATZLAWICK, Paul y otros. ¿Es real la realidad?. Editorial Herder S.A., Barcelona, 1985. 